\title{
ESTABELECIMENTO DE ESPÉCIES VEGETAIS EM UM INSELBERG GRANÍTICO DE MATA ATLÂNTICA
}

\section{Vegetable species establishment in one Inselberg granitic of forest atlantic's domain}

\author{
Túlio Dornas de Oliveira ${ }^{1}$ \\ Marilene Cardoso Ribeiro ${ }^{2}$ \\ Ivan Luiz Leite Costa ${ }^{2}$ \\ Flávia Santos Faria ${ }^{3}$ \\ José Eugênio Côrtes Figueira ${ }^{3}$
}

\section{Resumo}

Os Inselbergs, ambientes largamente presentes na Mata Atlântica, são afloramentos rochosos, caracterizados por serem ecossistemas altamente inóspitos para o estabelecimento de plantas. Neste estudo, desenvolvido em um Inselberg de domínio de Mata Atlântica no Centro-oeste do Estado de Minas Gerais, averiguamos como o geomorfologia e as áreas das ilhas de vegetação interferiram no estabelecimento das espécies vegetais. Constatamos que o estabelecimento das plantas está diretamente ligado ao tipo de micromelevo presente, e que as ilhas de vegetação com áreas maiores comportavam um maior número de espécies $(\mathrm{r}=$ 0.754, $\mathrm{n}=98, \mathrm{P}<0.001)$. Observamos que 0 acúmulo de espécies nas áreas de topo $(Z=0,246)$ do Inselberg é maior que nas áreas de encosta $(Z=0,132)$, por outro lado, o acúmulo de espécies vegetais dos Inselberg estudado mostrou-se $(Z=0,168)$ menor ao do Parque Nacional do Itatiaia $(Z=0,336)$.

Palavras-chave: Inselberg; Ilhas de vegetação; Mata Atlântica.

\section{Abstract}

The Inselbergs are rocky outcrop, environments widely present in Forest Atlantic. This study developed in one Inselberg (granite-outcrop) in Forest Atlantic's domain in center-west of State Minas Gerais, Brazil. We checked as geomorphology and the area of vegetation patches interfere in the vegetable species establishment. We conclude that plants establishment is straight connected to the kind of existent microrelief and the vegetation patches with biggest areas fit a large number of species $(r=0.754, n=98, P<0.001)$. We also observed that accumulation of species in areas in the Inselbergs' top $(Z=0,246)$ is bigger than in slope ( $Z$ $=0,132)$. On the order hand, the accumulation of species in this Inselberg show smaller $(Z=0,168)$ compared to accumulate Inselbergs' vegetable species in Parque Nacional do Itatiaia $(Z=0.336)$.

Keywords: Inselbergs; Islands vegetable; Forest Atlantic.

1 Bacharel em Ecologia - Laboratório de Ecologia de Populações, Sala I3 242, Departamento de Biologia Geral, Instituto de Ciências Biológicas Universidade Federal de Minas Gerais. Av. Presidente Antônio Carlos 6627, CEP31270-901 Belo Horizonte - MG, Brasil.

E-mail: tuliodornas@yahoo.com.br

2 Laboratório de Ecologia de Populações - ICB/UFMG,

2 Laboratório de Sistemática Vegetal - Departamento de Botânica - ICB/UFMG,

3 Prof. Dr. Departamento de Biologia Geral, Laboratório de Ecologia de Populações ICB/UFMG. 


\section{Introdução}

A Mata Atlântica é um dos biomas mundiais mais representativos da biodiversidade do planeta. Com mais de 20 mil espécies de plantas, metade delas endêmicas, e ainda abrigando 1,6 milhão de espécies animais, a distribuição da Mata Atlântica restringe-se a apenas 7,81\% de toda sua extensão original. É considerado o segundo bioma mais ameaçado do mundo, perdendo apenas para as quase extintas Florestas da Ilha de Madagascar (SCHAFFER; PROCHNOW, 2002). Diante dessas condições, o Bioma Mata Attântica é considerado um hot spot da biodiversidade mundial (MYERS et al., 2000).

Uma característica marcante da Mata Atlântica é sua grande diversidade ambiental (CÂMARA, 1992). Devido às irregularidades nas distribuições das chuvas, aliado à diversificada estrutura geomorfológica, o que se tem é uma ampla multiplicidade de hábitats: florestas úmidas, florestas semi e inteiramente decíduas, manguezais, restingas, campos de altitude e até campos rupestres (RIZZINI, 1997).

Dentre estes hábitats, destacam-se os Inselbergs, afloramentos rochosos nos topos de serras e montanhas, que apresentam características físicas e microclimáticas bastante adversas. A ausência de solos, baixa retenção de água, escassez de nutrientes, dificuldade para fixação de raízes, exposição ao vento e calor são condições limitantes para o crescimento de plantas nestes locais (LARSON et al., 2000). Devido a essas condições restritivas, as espécies de plantas rupícolas tolerantes têm um crescimento lento e gradual, abrangendo espécies cujos indivíduos atingem expressiva longevidade (ALVES, 1994). No entanto, indivíduos de outras espécies são capazes de se fixar à superfície lisa e muitas vezes íngreme das rochas. Essas espécies pioneiras formam pequenos "tapetes", cuja presença facilita a ocorrência de espécies sucessoras menos tolerantes (LARSON et al., 2000). Como resultado da sucessão, formam-se ilhas de vegetação, manchas de vegetação de tamanhos vari- áveis compostas de inúmeras espécies e indivíduos, assim como uma única espécie com um ou vários indivíduos. Estas ilhas de vegetação estão condicionadas tanto pela topografia local, como também pela presença de espécies facilitadoras, tal qual ocorre no Planalto do Itatiaia (RIBEIRO; MEDINA, 2002).

Nos últimos 20 anos, estudos sobre este tipo de vegetação têm ganhado destaque, pois devido ao alto grau de isolamento do fogo, e à sua inutilidade em atividades agropecuárias, mantêm-se bem preservadas (POREMBSKI et al., 1998).

Deste modo, dada a destacável relevância biológica atribuída aos Inselbergs, ambientes ameaçados pelo comércio de pedras ornamentais (Campello, 2000) e a necessidade de estudos de caráter ecológico sobre a Mata Atlântica, realizamos um trabalho de pesquisa em um Inselberg localizado na Serra da Canoa, no entorno da Estação Ecológica da Mata do Cedro, um importante remanescente de Mata Atlântica, situado no limite dos municípios de Cláudio e Carmopólis de Minas, no Centro-oeste do Estado de Minas Gerais, Brasil.

O objetivo desse estudo foi o de avaliar quais as características do relevo que determinam o estabelecimento da cobertura vegetal do Inselberg; e se a área das ilhas de vegetação têm relação com a variação na riqueza em espécies vegetais delas.

\section{Materiais e Métodos}

\section{Área de estudo}

A Estação Ecológica da Mata do Cedro (EEMC) localiza-se na bacia do Rio Pará, afluente do Rio São Francisco. A Serra da Canoa situa-se a menos de 800 metros a norte da EEMC (Figura 1) e atualmente vem sendo trabalhada junto ao órgão ambiental estadual sua inserção à área da EEMC. 
Figura 1. Desenho esquemá tico loca lizando com uma seta o Inselberg estudado e a Esta ção Ecológica Mata do Cedro.

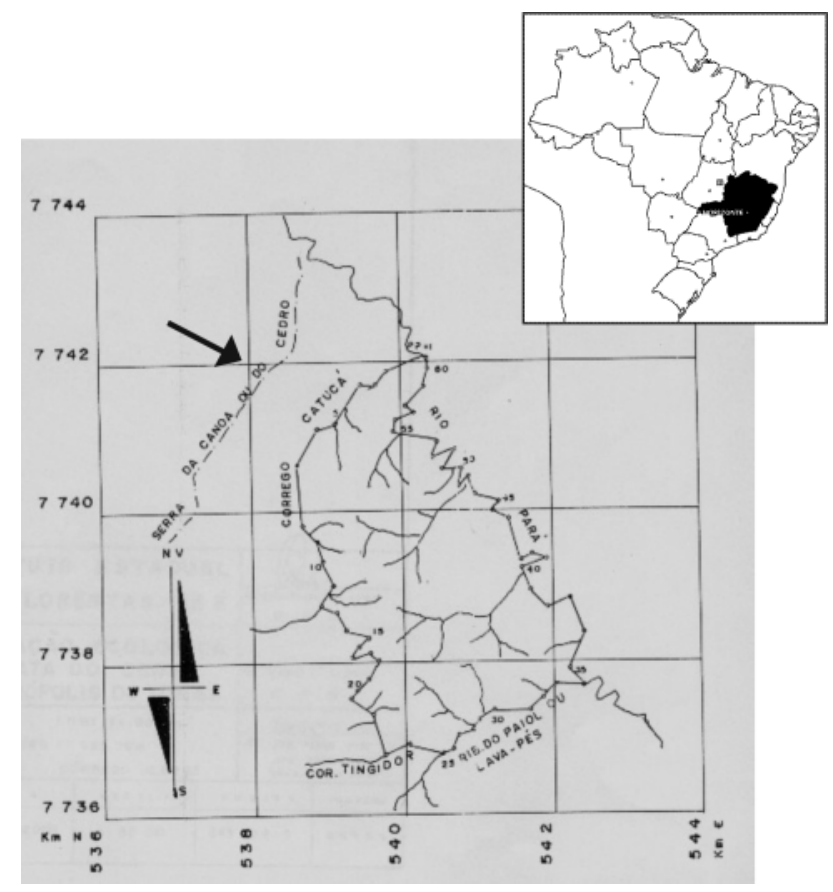

Os Inselbergs são abundantes na região, mas muitos deles encontram-se sob ação da exploração comercial do granito para produção de pedras ornamentais. O In selberg estudado (20025'16.8”S - 44038'11.6”W) apresenta diversas espécies animais como répteis, pássaros e artrópodes e ainda várias espécies vegetais, principalmente de Velloziaceae, Bromeliaceae, Melastomataceae e Cactaceae. Entre abril e maio de 2003, amostramos 98 ilhas de vegetação neste Inselberg, com áreas variando entre $0,002 \mathrm{~m}$ $729 m_{-}$. Estas ilhas de vegetação, segundo critério de categorização utilizado por Ribeiro e Medina (2000), estão situadas sobre os seguintes microrrelevos: canaletas, superfícies lisas, fissuras, panelas e superfícies cobertas de pedras. Em cada uma das ilhas de vegetação (unidade amostral), foram identificadas as espécies vegetais e medidas a altitude, a área, a profundidade do solo e a inclinação da rocha matriz.

Para verificar se a variação na riqueza em espécies de plantas poderia ser explicada pelas características dos diferentes microrrelevos, usamos uma análise de regressão múltipla "step-wise". Para analisar possível efeito da inclinação do Inselberg (que provavelmente determina a existência dos diferentes microrrelevos, bem como sua capacidade de reter matéria orgânica, nutrientes e solos) sobre a riqueza em espécies, fizemos duas análises de regressão linear simples, pelas quais buscamos averiguar se havia alguma dependência da variação de riqueza em espécies às áreas das ilhas de vegetação, para altitudes menores $1100 \mathrm{~m}$ (corresponde à encosta, local com maior inclinação) e maiores que $1100 \mathrm{~m}$ (corresponde ao topo do Inselberg, local mais plano). Para as análises, usamos o programa Systat 5.0.

\section{Resulta dos e Discussão}

\section{Influência do Microrrelevo}

O Inselberg estudado tinha cerca de $200 \mathrm{~m}$ da base ao topo $(940 \mathrm{~m}$ a $1150 \mathrm{~m})$, com inclinação variando entre $35^{\circ}$ (encosta) e $0^{\circ}$ graus (topo). Foram encontradas 17 espécies de angiospermas e uma de pteridófita (Tabela 1). As famílias mais freqüentes foram Cactaceae, com a espécie Pilocereus sp, ocorrendo em 51 das ilhas de vegetação (52\%) e Velloziaceae com 2 espécies, ocorrendo em 66 ilhas de vegetação (68\%), sendo que Vellozia sp1 estava presente em todas elas. Destas 66 ilhas de vegetação, 28 delas (42\%) apresentavam Vellozia sp1 cobrindo mais de 50\% da área das ilhas. Estas famílias inclusive são consideradas entre as de maior freqüência nos Inselbergs graníticos da região neotropical (POREMBSKI et al., 1997). 


\section{Tabela 1. Listas das espécies vegetais observadas no Inselberg estudado e os} microrrelevos em que elas foram encontradas.

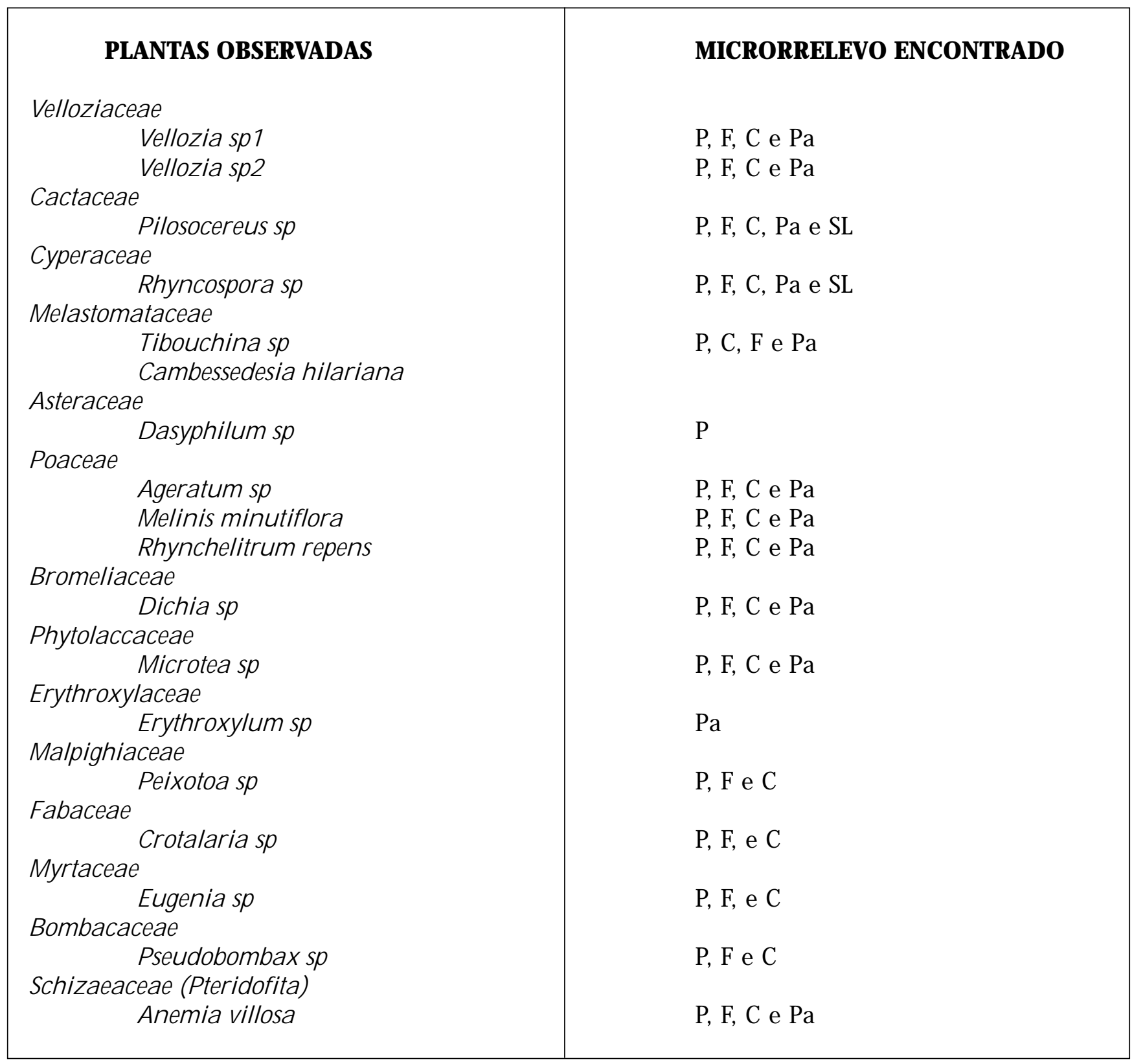

As análises de microrrelevos revelaram que das 98 ilhas de vegetação amostradas, 43 situavam-se em microrrelevos com substrato pedregoso, 47 em fissuras, 16 em canaletas, 18 em panelas e 12 em superfícies lisas (em algumas ilhas havia mais de um tipo de microrrelevo) (Tabela 2). O microrrelevo de substrato pedregoso contin- ha todas as 18 espécies de plantas, as fissuras apresentaram 15 espécies e as canaletas e as panelas apresentaram 14 e 13 espécies respectivamente. Apenas 2 espécies foram encontradas sobre superfície lisa (Tabela 1), demonstrando o quanto 0 substrato deste microrrelevo é difícil de ser utilizado em comparação aos demais. 
Tabela 2. Número de ocorrência de microrrelevos nas ilhas de vegetação e número de espécies vegetais em cada um dos microrrelevos. Notar o número reduzido de espécies no microrrelevo de superfície lisa.

\begin{tabular}{|l|l|l|}
\hline MICRORRELEVOS & $\begin{array}{l}\text { No DE OCORRÊNCIA NAS } \\
\text { ILHAS DE VEGETAÇÃO* }\end{array}$ & $\begin{array}{l}\text { N. }{ }^{\circ} \text { DE ESPÉCIES } \\
\text { PRESENTES }\end{array}$ \\
\hline Fissura & 47 & 15 \\
Pedregoso & 43 & 18 \\
Panela & 18 & 13 \\
Canaleta & 16 & 14 \\
Superfície lisa & 12 & 2 \\
\hline
\end{tabular}

* Poderia haver mais de um microrrelevo por ilha de vegetação.

Estas duas espécies eram Pilocereus sp (Cactaceae) e Rhyncospora sp (Cyperaceae), sendo que esta última apresentava o papel de espécie pioneira, pois era capaz de se estabelecer na superfície lisa, formando um extenso tapete. Segundo Porembski et al. (1997), esta é uma característica marcante entre os representantes da família das ciperáceas encontradas em Inselbergs pelo mundo. As formações destes tapetes permitiam o estabelecimento de plântulas de Vellozia sp1 sobre elas, demonstrando a atuação de Rhyncospora sp como espécie facilitadora para a colonização e estabelecimento de outras espécies, condição freqüente e de grande relevância para o estabelecimento de plantas nestes ambientes rochosos (POREMBSKI et al., 1998; LARSON et al., 2000). Este papel de facilitador também é realizado por musgos e liquens geralmente encontrados nos Inselbergs (POREMBSKI et al., 1997).

A presença de raízes mais fortes e com maior poder de penetração na rocha deve ser estratégia presente em Pilocereus sp e Rynchospora sp, pois facilitaria e auxiliaria na fixação e absorção de recursos neste tipo de substrato. Além disso, Collins et al. (1989) propõem que em afloramentos de granitos do sudeste dos Estados Unidos, devido à intensificação da acidificação dos solos das ilhas de vegetação, à medida que essas aumentam sua área, associada à ação mecânica das raízes, aconteceria um processo de degradação da rocha matriz, possibilitando a formação de solos mais profundos e de novos sítios de estabelecimentos de plântulas sobre a rocha matriz. Possivelmente, essas duas espécies de plantas também devem se beneficiar de tais condições para fixarem-se sobre a rocha neste tipo de microrrelevo.

\section{Relação Espécie-Área}

A variação em riqueza de espécies vegetais correlacionou positiva, linear e significativamente com a profundidade do solo nas ilhas de vegetação ( $r=0.495 \mathrm{n}=98, \mathrm{P}<0,001)$ (Figura $2 b$ ) no Inselberg estudado, ocorrendo o mesmo para as áreas das ilhas de vegetação, sendo esta última uma correlação mais forte $(r=0.754, n=98, P<$ 0.001) (Figura 2a). O mesmo foi apresentado por Collins et al. (1989) e Houle (1990) em estudos para afloramentos graníticos. Estudos nos afloramentos areníticos no Tepui Roraima na Venezuela também demonstram uma forte e positiva correlação entre riqueza de espécies vegetais, profundidade do solo e as áreas da ilhas de vegetação, porém esta é exponencial (MICHELANGELU, 2000). 


\section{Figura 2. Relação entre o número de espécies com a área (a) e profundidade do solo (b) das ilhas de vegeta ção.}

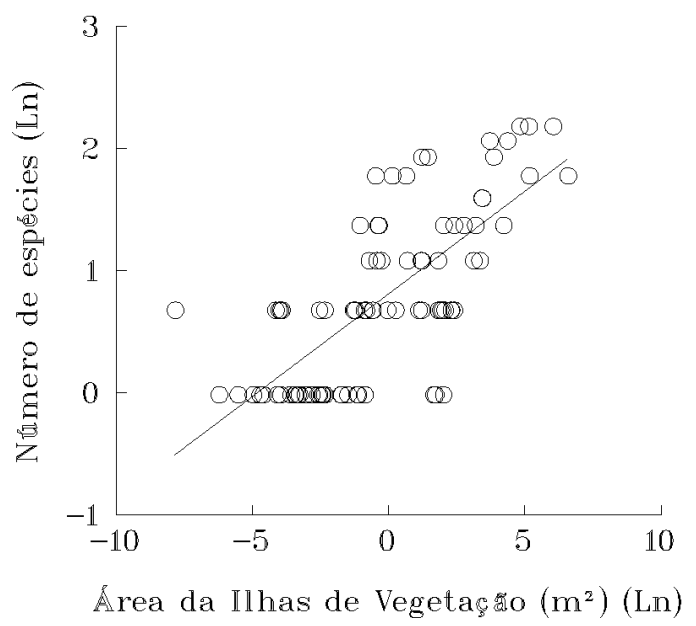

Nestes afloramentos do Tepui Roraima, os solos das ilhas são constituídos por grãos de areia depositados em canais alongados na rocha formados pela ação da chuva, onde, por sua vez, se estabeleceriam as plantas, não havendo a formação de tapetes na rocha matriz, ao contrário dos afloramentos de granitos. Segundo Michelangelli (2000), esta diferenciada composição e formação do solo poderiam explicar estas diferentes correlações entre esses dois tipos de afloramentos.

Ainda no Inselberg estudado, foi verificado que a chance de se encontrar mais de um microrrelevo e solos mais profundos $(r=0.678, n$ $=98 \mathrm{P}<0.001)$ em ilhas de vegetação com áreas maiores aumentava. Deste modo, à concentração de microrrelevos pode estar favorecendo o acúmulo de matéria orgânica, diminuindo a lixiviação desta nas ilhas de vegetação, permitindo, assim, a presença de um solo úmido e nutritivo por um maior período de tempo, como observado também por Michelangelli (2000) nos afloramentos do Tepui Roraima.

Desta maneira, quando comparada às ilhas de menor área, nas quais os solos são mais rasos, a germinação das sementes em ilhas maiores e que têm solos mais profundos é favorecida,

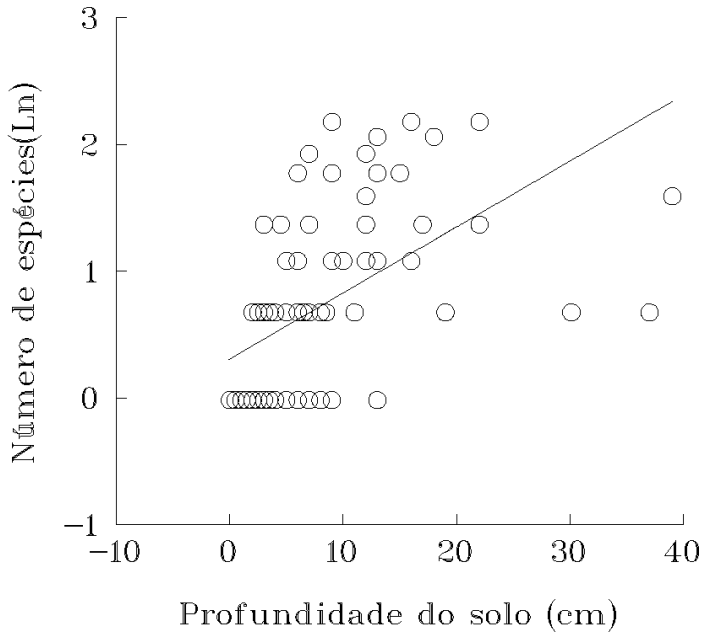

assim como a fixação e o crescimento das raízes, facilitando consideravelmente 0 estabelecimento das plantas. Ribeiro e Medina (2000) também mostraram em Inselbergs graníticos no Planalto do Itatiaia que a área das ilhas de vegetação apresentava-se como fator mais relevante para o estabelecimento das espécies vegetais no Inselberg estudado.

Uma consideração importante observada no estudo do Inselberg da Serra da Canoa foi que o número de espécies aumenta mais rapidamente com a área das ilhas situadas acima de $1100 \mathrm{~m}(\ln S=0.240 \ln \mathrm{A}+1.09, \mathrm{r}=0.882, \mathrm{n}=45$, $\mathrm{P}<0.0001)$, comparativamente às ilhas de mesma área situadas abaixo de $1100 \mathrm{~m}(\ln \mathrm{S}=0.132$ $\ln \mathrm{A}+0.672, \mathrm{r}=0.699, \mathrm{n}=53, \mathrm{P}<0.001$ ) (Figura $3)$. Isso sugere que as condições para colonização dos microrrelevos situados nas encostas do Inselberg são mais restritivas do que as do topo. Uma explicação para tal condição seria a presença de numerosas panelas, microrrelevo predominante nas ilhas de vegetação do topo do Inselberg (14 das 18 amostradas), os quais têm solos profundos e menos propensos à lixiviação (inclinação entre $0^{\circ}$ e $5^{0}$ ) que ofereceriam condições mais favoráveis para a colonização das espécies vegetais. 
Figura 3. Variação no número de espécies de acordo com a altitude. A linha preta (pontos brancos) mostra o número de espécies nas ilhas acima de 1100 metros de altitude enquanto que a linha tracejada (pontos negros) faz referência a número de especies abaix o de 1100 metros.

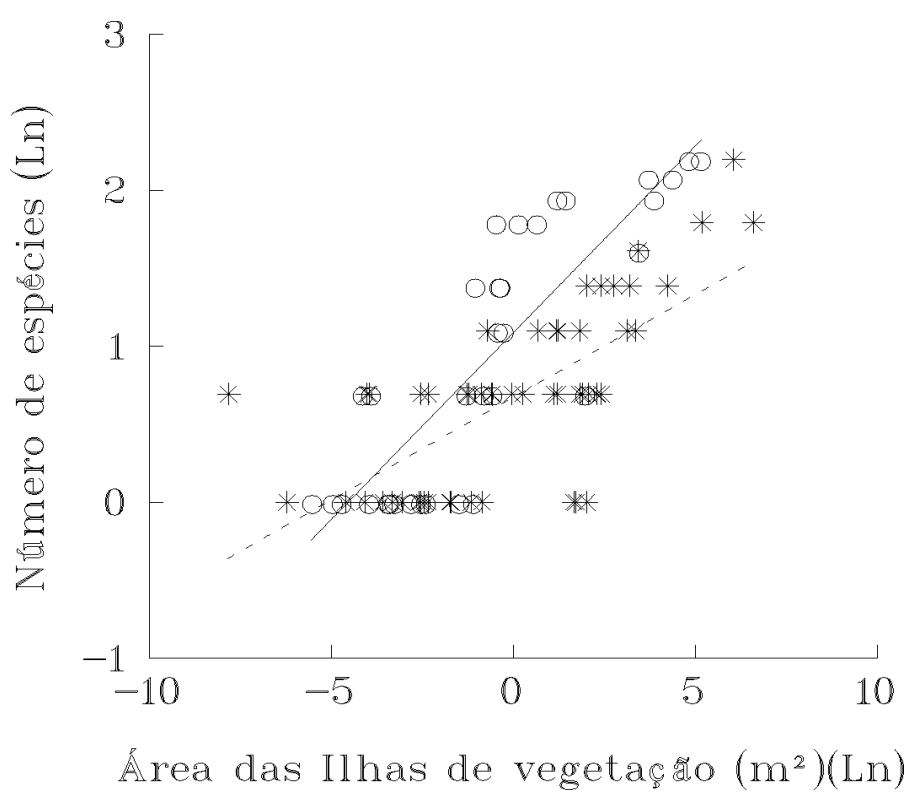

Por outro lado, a taxa de acúmulo de espécies vegetais do Inselberg estudado foi menor $(\mathrm{Z}=0.168)$ do que a obtida por Ribeiro e Medina (2000) $(Z=0.336)$ nos Inselbergs do Planalto do Itatiaia. Isto sugere que alguns fatores tais como a qualidade ambiental das ilhas e/ou o número de espécies capazes de colonizar Inselbergs e/ou a diversidade de micro-hábitats são inferiores no Inselberg da Serra da Canoa. Portanto, isso nos sugere indicações de um grau maior de adversidade ambiental no local de estudo que dificultaria a colonização e o estabelecimento de espécies vegetais neste Inselberg.

Sobretudo, o estudo demonstrou que o Inselberg da Serra da Canoa mantém uma comunidade florística diferenciada dentro do domínio de Mata Attântica regional, permitindo a presença de cactáceas, ciperáceas e as velosiáceas, espécies rupestres e xerófilas Porembski et al. (1997), as quais em conjunto com outras famílias: bromeliáceas, melastomatáceas, dentre outras, permitem a manutenção de uma grande diversidade da flora local.

Porembski e colaboradores (1997) destacam que um dos fatos mais marcantes nos Inselbergs de Mata Atlântica brasileiros são as suas expressivas _ e _-diversidades. Estes, associados ao papel de refúgio de espécies xerófilas e de centro de endemismo definido para os Inselbergs neotropicais por Parmetier (2003) mostram-se fortes e plausíveis justificativas para implementação de estratégias conservacionistas para os Inselbergs sul-americanos.

Deste modo, percebe-se nitidamente que o Inselberg da Serra da Canoa trata-se de um ambiente de vital importância biológica regional, sendo que a incorporação de sua área à Estação Ecológica Mata do Cedro aponta-se como uma importante medida para a preservação da Mata Atlântica regional, garantindo-se, ainda, a possibilidade da realização de novos estudos.

\section{Agradecimentos}

Agradecemos ao Prof. Rogério Parentoni Martins e à doutoranda Flávia de Sousa Coelho pelas sugestões na elaboração do manuscrito; ao Laboratório de Sistemática e Taxonomia Vegetal do Departamento de Botânica do ICB/UFMG na identificação dos exemplares coletados. Agradecemos também a Caio Dornas de Oliveira, pelo auxílio nos trabalhos de campo. 


\section{Referências}

ALVES, R.J.V. Morphological age determination and longevity in some Vellozia population in Brazil. Folia Geobotanica Phytotaxa Praha v.29, p. 55 - 59, 1994.

CÂMARA I.G. Plano de Ação para a Mata Atlântica. São Paulo, Fundação SOS Mata Atlântica / Editora Interação, 1992.

CAMPELLO, M.S. Caracterização tecnológica de granitos ornamentais. Belo Horizonte, 2000. 123fls. Dissertação de Mestrado - Universidade Federal de Minas Gerais.

COLLINS, S. L.; MITCHEL, G.S.; KLAHR S.C. Vegetation-environment relationships in a rock outcrop community in Southern Oklahoma. American Midland Naturalist v.122, p. 339-348, 1989.

HOULE, G. Species-area relationship during primary succession in granite outcrops communities. American journal of Botany v.77, p. 1433-1439, 1990.

LARSON D.W,; MATTHES U.; KELLY P.E. Cliff Ecology: Patterns and Process in Cliff Ecosystems. Cambridge University Press, Cambridge 340p, 2000.

MICHELANGELI, F.A. Species composition and species-area relationships in vegetation isolates on the summit of sanstone mountain in southern Venezuela. Journal of Tropical Ecology v. 16, p.69-82, 2000.

MYERS, N.; MTTERMEIER, R.A.; MTTERMEIER, C.G.; KENT, J.; FONSECA, G.A.B. Biodiversity hotspots for conservation priorities. Nature v.403, p.853-858, 2000.
PARMENTIER, I. Study of the vegetation composition in three Inselbergs from Continental Equatorial Guinea (Western Central Africa): Effects of site factors and position relative to forest fringe. Belgian Journal of Botany v.136, p.63-72, 2003.

POREMBSKI, S.; SEINE, R.; BARTHLOTT, W. Inselberg vegetation and biodiversity of granite outcrops. Journal of the Royal Society of Western Australia v. 80, p. 193-197, 1997.

POREMBSKI, S.; MARTINELLI, G.; ONLEMULERR, R.; BARTHLOT, W. Diversity and ecology of saxicolous vegetation mats on Inselbergs in Brazilian Atlantic forest. Diversity and Distributions. v.4, p. 107 - 119, 1998.

RIBEIRO, K.T.; MEDINA, B. M. O. Estrutura, Dinâmica e Biogeografia de Ilhas de Vegetação Sobre Rocha do Planalto do Itatiaia, RJ. IBAMA/UFRRJ Parque Nacional do Itatiaia. Boletim $\mathrm{n}$ 을, Itatiaia 84p., 2002

RIZZINI, C.T. Tratado de Fitogeografia do Brasil, aspectos ecológicos, sociológicos e florísticos. $2^{\circ}$ edição. Editora Âmbito Cultural, Rio de Janeiro - RJ, 747p., 1997.

SHAFFER, W. B.; PROCHNOW M. Mata Atlântica e Você. Como preservar, recuperar e se beneficiar da mais ameaçada floresta brasileira. Brasília-DF 155p. 2002.

Recebido em / Received in: 18.08.2004 Aceito em / Accepted in: 19.10.2004 